\title{
Research Article: Personal and socio-economic profile of dairy farmer in Akola and Washim district of Maharashtra
}

\author{
REWENDRA KUMAR SAHU, Y. B. SHAMBHARKAR AND M. L. SHARMA
}

Article Chronicle: Received : 17.07.2017; Accepted : 01.08.2017

KEY Words : Dairy farmer, Socio-economic Profile, Livestock
SUMMARY : An attempt has been made in this paper to investigate the socio-personal, socio-economic and Socio-psychological profile of dairy farmer in Akola and Washim district of Maharashtra during the year 2015-2016. Total 140 farmers were selected from two blocks namely Akola and Washim from above districts as respondents by using random sampling method.Data were collected by personal interview with help ofwell structured interview schedule and data were subjected to appropriate statistical analysis. In this investigation it is found that, out of 140 respondents majority $(42.14 \%)$ were in middle age group, (38.57\%) of them belonged to high school level of education, $(56.43 \%)$ of them had 5 to 8 members in their Family, more than half (52.86\%)of respondents had medium term credit acquisition, $(82.86 \%)$ of them had Dairy + Agriculture as occupation, (46.43\%) of respondent had Rs 1, 00,001 to $1,50,000 /$ - annual income, $(65.72 \%)$ dairy farmer had 08 to 26 years of dairy farming experiences, $(72.86 \%)$ of dairy farmer had categories under medium level of scientific orientation and more than three fourth $(77.14 \%)$ of them had also categories under mediumlevel of market orientation.

How to cite this article : Sahu, Rewendra Kumar, Shambharkar, Y. B. and Sharma, M. L. (2017). Personal and socio-economic profile of dairy farmer in Akola and Washim district of Maharashtra. Agric. Update, 12 (TECHSEAR-6) : 1688-1691; DOI: 10.15740/HAS/AU/12. TECHSEAR(6)2017/1688-1691.
Author for correspondence :

\section{REWENDRA KUMAR}

\section{SAHU}

Department of Agricultural Extension, Indira Gandhi

KrishiVishwavidyalaya, RAIPUR (C.G.) INDIA

Email: rewendrasahu@ gmail.com 